\title{
Sera Şartlarında Yetiştirilen Çilekte (Fragaria $x$ ananassa L.) Organik Gübre Uygulaması İle Bombus Arılarının ( Bombus Terrestris) Kullanımının Meyvelerin Biyokimyasal İçerikleri Üzerine Etkileri
}

\author{
The Effects of Using Organic Fertilizer and Bumblebees (Bombus Terrestris) on the \\ Biochemical Contents of Fruits in Greenhouse-grown Strawberry (Fragaria x ananassa L.)
}

\author{
Gürsel ÖZKAN* \\ Atatürk Üniversitesi, Ziraat Fakültesi, Bahçe Bitkileri Bölümü, 25240-Erzurum
}

• Geliş tarihi / Received: 05.03.2019 • • Düzeltilerek geliş tarihi / Received in revised form: 03.05.2019 • Kabul tarihi / Accepted: 15.05 .2019

Öz

$\mathrm{Bu}$ çalışma, 2017 yılında sera şartlarında çilek yetiştiriciliğinde organik gübre uygulaması ile Bombus arılarının kullanımının meyvelerin biyokimyasal içerikleri üzerine etkilerini araştırmak amacıyla Erzurum Atatürk Üniversitesi Bitkisel Üretim Uygulama ve Araştırma Merkezine ait 1sı kontrollü serada yürütülmüştür. Bitkisel materyal olarak Albion çilek çeşidine ait 1. sınıf frigo fideler kullanılmıştır. Deneme tesadüf parselleri deneme desenine göre 3 tekerrürlü ve her tekerrürde 30 bitki olacak şekilde kurulmuştur. Denemede yetiştirme ortamı olarak kokopit kullanılmıştır. Kontrol bitkilerinin dışında kalan bitkilere Roa Plus Organik Gübresi önerilen dozda iki haftada bir olmak üzere uygulanmıştır. Denemenin kurulumundan 4 ay sonra ilk örnekler alınarak seraya 3 koloni Bombus arısı yerleştirilmiştir. Bundan 1,5 ay sonra yeniden örnekler alınıp karşılaştırma yapılmıştır. Araştırmada meyvelerin SÇKM, toplam şeker, vitamin C, Malik asit, $\mathrm{pH}$ ve Titre Edilebilir Asit içerikleri belirlenmiştir. Sonuç olarak Bombus arılarının faaliyeti ile hem kontrol hem de organik gübre uygulamasına ait meyvelerde incelenen parametrelerin çoğunda artış olduğu tespit edilmiştir.

Anahtar kelimeler: Bombus Terrestris, Çilek, Erzurum, Organik Gübre, Sera

\begin{abstract}
This study was carried out in the temperature controlled greenhouse of Erzurum Atatürk University Plant Production Application and Research Center in 2017 to investigate the effects of the use of organic fertilizers in strawberry cultivation in greenhouse conditions on biochemical content of fruits. As a vegetable material, first class frigo seedlings belonging to Albion strawberry variety were used. The experiment was designed with 3 replications according to the experimental design and 30 plants in each replica. Kokopit was used as the growing medium in the experiment. Roa Plus Organic Fertilizer was applied to the plants outside the control plants every two weeks at the recommended dose. Four months after the experiment, the first specimens were taken and 3 colony bumblebees were placed in the greenhouse. After 1.5 months, samples were taken and compared. In the study, the content of TSS, total sugar, vitamin $C$, Malic acid, $p H$ and Titratable Acid were determined. As a result, it was determined that most of the parameters examined in the fruits of both control and organic fertilizer application with the activity of Bumblebee bees.
\end{abstract}

Keywords: Bombus Terrestris, Strawberry, Erzurum, Organic Fertilizer, Greenhouse

* Gürsel ÖZKAN; gozkan08@atauni.edu.tr; Tel: (0442) 231 16 80; orcid.org/ 


\section{Giriş}

Çilek tüm dünyada severek tüketilen üzümsü meyveler arasındadır. Rosales takımının Rosaceae familyası içerisinde Fragaria cinsine dahil olan çileğin, Avrupa, Asya, Güney ve Kuzey Amerika'da 12 kadar türü doğal olarak yetişmektedir. Kültürü yapılan çilek çeşitleri, Kuzey Amerika orijinli $F$. virginiana ve Güney Amerika orijinli $F$. chiloensis türlerinin melezi Fragaria $x$ ananassa türü içerisinde bulunmaktadır. ABD, Avrupa, Güney ve Doğu Afrika ülkeleri, Yeni Zelanda, Avusturalya ve Japonya'da yoğun olarak yetiştirilen çilek, birçok tüketim imkanına sahiptir. Otsu yapıda ve çok yıllık bir meyve türü olması, üzerinde birçok 1slah çalışmalarının yapılması ile de dünya üzerinde üretimi giderek artmaktadır (Ağaoğlu, 1986; Aybak, 2005).

Çilek yetiştiriciliği Türkiye'de küçük ve orta ölçekli işletmeler ve aile işletmeleri tarafından tercih edilmektedir. Farklı iklim özelliklerine sahip olan Türkiye'de üretimin y1l içerisine yayılmış olması ilk ve son turfanda olarak çilek yetiştiriciliğine imkan vermektedir. Ülkede iklimin olumsuz etkisinden dolayı bitkisel üretimin sınırlı olduğu illerin başında Erzurum gelmektedir. Doğu Anadolu bölgesinde 39- 55 kuzey enlemi 41-16 doğu boylamı üzerinde bulunan Erzurum ili Türkiye'nin rakımı en yüksek $(1850-1980 \mathrm{~m})$ ve en soğuk illerinden birisidir (Özkan, 2012).

Erzurum ilinde çilek yetiştiriciliği özellikle son turfanda olarak yapılmaktadır. Vejetasyon periyodu haziran ile Ekim ayları arasında oldukça k1sa bir süreyi kapsamaktadır. $\mathrm{Bu}$ nedenle örtü altında çilek yetiştiriciliği bu periyodu uzatmak ve daha fazla gelir elde etmek amaciyla bir zorunluluk haline gelmektedir. İlde örtü altında çilek yetiştiriciliği yapan işletme sayısı oldukça sınırlıdır. $\mathrm{Bu}$ işletmelerde iklimlendirme istemi olmadığından uzun geçen kış sezonunda üretim mümkün değildir. Ayrıca sera yetiştiriciliğinde en önemli problemlerden biri de yeterli hava akımının olmamasından dolayı çiçeklerin tozlanamaması ve bu nedenle küçük ve şekilsiz, kalitesi düşük meyvelerin elde edilmesidir. $\mathrm{Bu}$ anlamda seralarda tozlanmayı sağlamak amacıyla ticari tozlayıcı olarak geniş ölçüde bombus arıları kullanılmaktadır (Mommaerts, 2011; Fliszkiewicz vd., 2011). Bombus arıları genellikle soğuk hava sicaklıklarında daha etkili olmaktadırlar (Paydas vd., 1998). Bombus arılarının kullanımıyla meyve iriliğinde ve kalitesinde gözle görülür artışlar meydana gelmektedir. Meyvelerin irileşmesinde tohumun önemli bir yeri vardır. Tohum ise iyi bir tozlanmadan sonra meydana gelmektedir. Bombus arılarının faaliyeti ile meyvelerdeki tohum artışı aynı zamanda meyvelerin hacimsel olarak artışını da sağlamaktadır. Sera şartlarında yetiştirilen tatlı biberlerde yapılan bir çalışmada bombus arıları tarafından ziyaret edilen çiçeklerden meydana gelen meyvelerde hem tohum sayısinin hem de meyve ağırlıklarının kontrole göre daha fazla olduğu belirlenmiştir (Rolda'n Serrano ve Guerra Sanz, 2006). Yine hiyarlarda yapılan bir çalışmada bombus arılarının etkinliği ile verimde artışlar meydana gelmiştir (Gajc-Wolska vd., 2011). Benzer şekilde sera şartlarında su kültüründe Selva çilek çeşidiyle yapılan bir çalışmada ise bombus arılarının kullanımıyla pazarlanabilir meyve miktarında önemli artış olduğu saptanmıştır (Dimou vd., 2008). Bombus arılarının kullanımı sera ile sınırlı değildir. Açık arazide meyve bahçelerinde kullanımı ile bal arılarının tozlanmaya etkilerine katk1 yaparak meyvelerin çekirdek sayılarında ve iriliklerinde artışlar meydana getirmektedir (Zisovich vd., 2012).

$\mathrm{Bu}$ çalışma ile iklimlendirme sistemine sahip seralarda ve organik şartlarda y1l boyu üretim gerçekleştirilmiştir. Sera yetiştiriciliğindeki önemli bir problemi ortadan kaldırmak için Bombus arı kolonileri kullanılmış ve Bombus arılarının meyvelerin biyokimyasal içerikleri üzerine etkilerinin belirlenmesi amaçlanmıştır.

\section{Materyal ve Yöntem}

\subsection{Materyal}

Araştırmada bitkisel materyal olarak yediveren çilek özelliğinde rakımı $600 \mathrm{~m}$ ve üzerindeki soğuk bölgeler için uygun, meyve kalitesi çok iyi, nakliyeye dayanıklı, hastalıklara dayanıklılığı en üst seviyede hoş kokulu ve aramosı yüksek Albion çilek çeşidine ait 1 . sınıf frigo fideler kullanılmıştır. Frigo fideler Antalya'da sertifikalı fide üretimi yapan özel bir firmadan temin edilmiştir.

\subsection{Yöntem}

$\mathrm{Bu}$ araştırma Atatürk Üniversitesi Bitkisel Üretim Uygulama ve Araştırma Merkezi bünyesinde bulunan 1s1 kontürollü $\quad\left(18-22^{\circ} \mathrm{C}\right)$ serada yürütülmüştür. Deneme tesadüf parselleri deneme desenine göre 3 tekerrürlü ve her tekerrürde 30 bitki olacak şekilde planlanmıştır. Yetiştirme ortamı olarak kokopit kullanılmıştır. Deneme süresince bütün bitkilere gerekli besin solusyonu 
verilmiştir. Ayrıca control bitkileri dışında kalan bitkilere ROA Plus organic gübresi önerilen dozda her 15 günde bir tekrarlanarak uygulanmıştır. Çalışmanın kurulumundan 120 gün (4 ay) sonra ilk örnekler alınarak, Agro Bio firmasindan temin edilen ve koloni başına 80 adet arı bulunan 3 adet Bombus ar1 kolonisi seranın uygun yerlerine yerleştirilmiştir. 45 günlük $(1,5$ ay) arı faaliyetinden sonra tekrar meyve örnekleri alınarak çilek meyvelerine ait usarelerde suda çözünebilir kuru madde, $\mathrm{C}$ vitamini, $\mathrm{pH}$, malik asit, titre edilebilir asitlik (sitrik asit cinsinden) ve toplam şeker analizleri yapılmış ve ilk örneklerle karşılaştırılmıştır.

Denemede çilek meyvelerinin suda çözünebilir kuru madde miktarı (SÇKM), toplam şeker, vitamin $\mathrm{C}$ (Askorbik asit), Malik asit, $\mathrm{pH}$ içerikleri "RQflex plus 10" cihazı ile test kitleri kullanılarak reflektometrik olarak ve titre edilebilir asit içerikleri ise $0,1 \mathrm{~N} \mathrm{NaOH}$ ile titrarsyon metoduyla belirlenmiştir (Özkan, 2012).

\section{Bulgular ve Tartışma}

$\mathrm{Bu}$ çalışmada genel literature uygun olarak bombus arılarının kullanımı ile hem kontrol hem de organik gübre uygulamalarına ait meyvelerde gözle görülür irilik ve bir örneklik tespit edilmiştir (Şekil 1, Şekil 2, Şekil 3, Şekil 4). Meyvelerin irilik ve üniform şekil oluşturmaları üzerine bombus arılarının faaliyetinin pozitif yönde etkili olduğu görülmektedir. Optimum tozlanmaya bağlı olarak meyvelerin albenisi daha yüksek olmuştur.

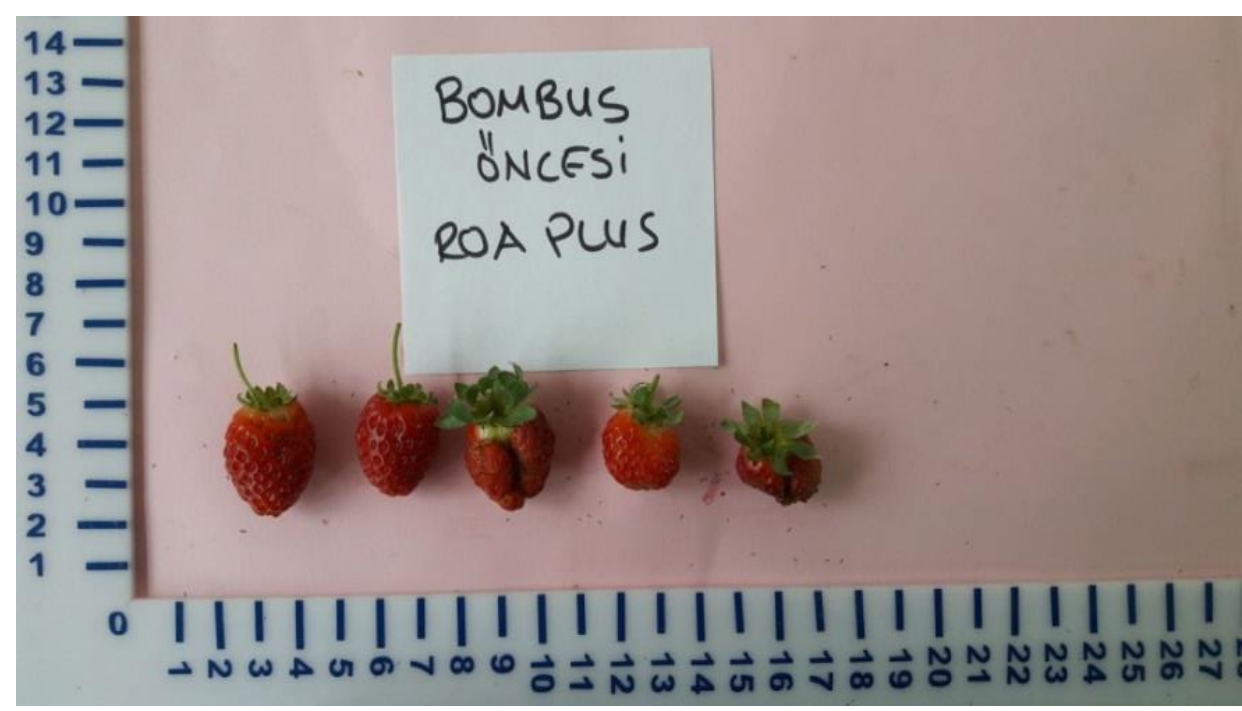

Şekil 1. Bombus arılarından önce Organik Gübre uygulamasına ait meyveler

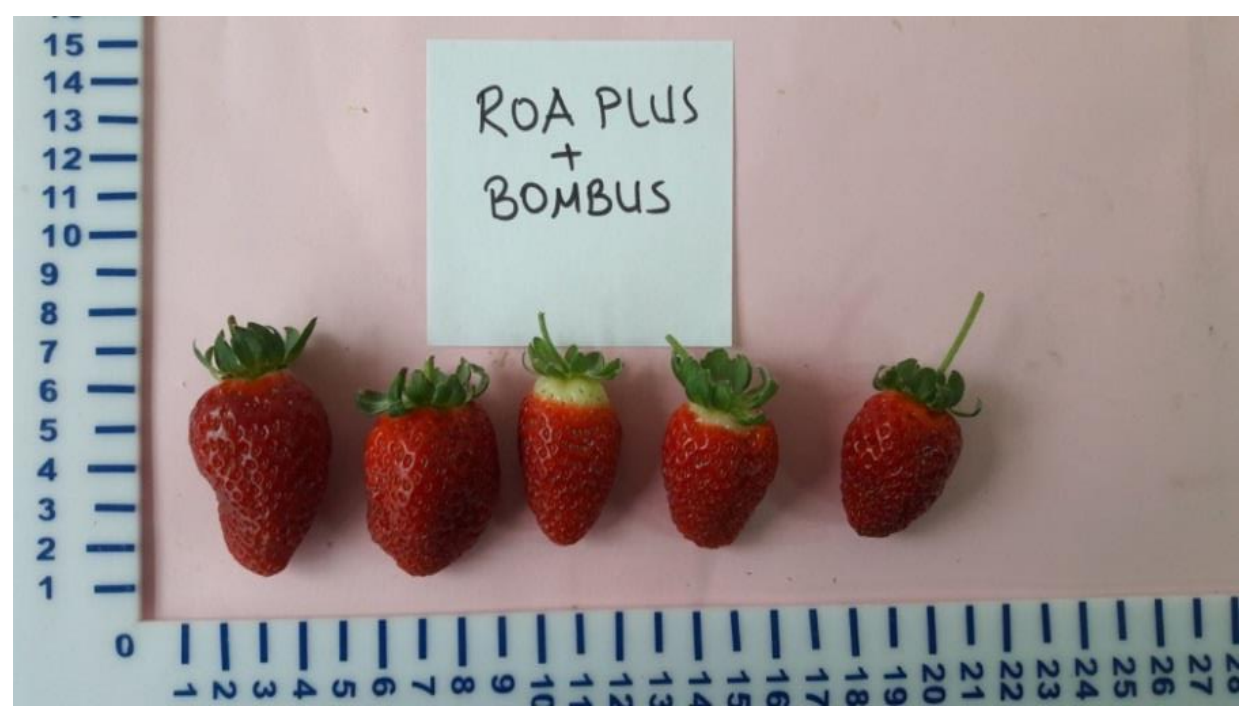

Şekil 2. Bombus arılarından sonra Organik Gübre uygulamasına ait meyveler 


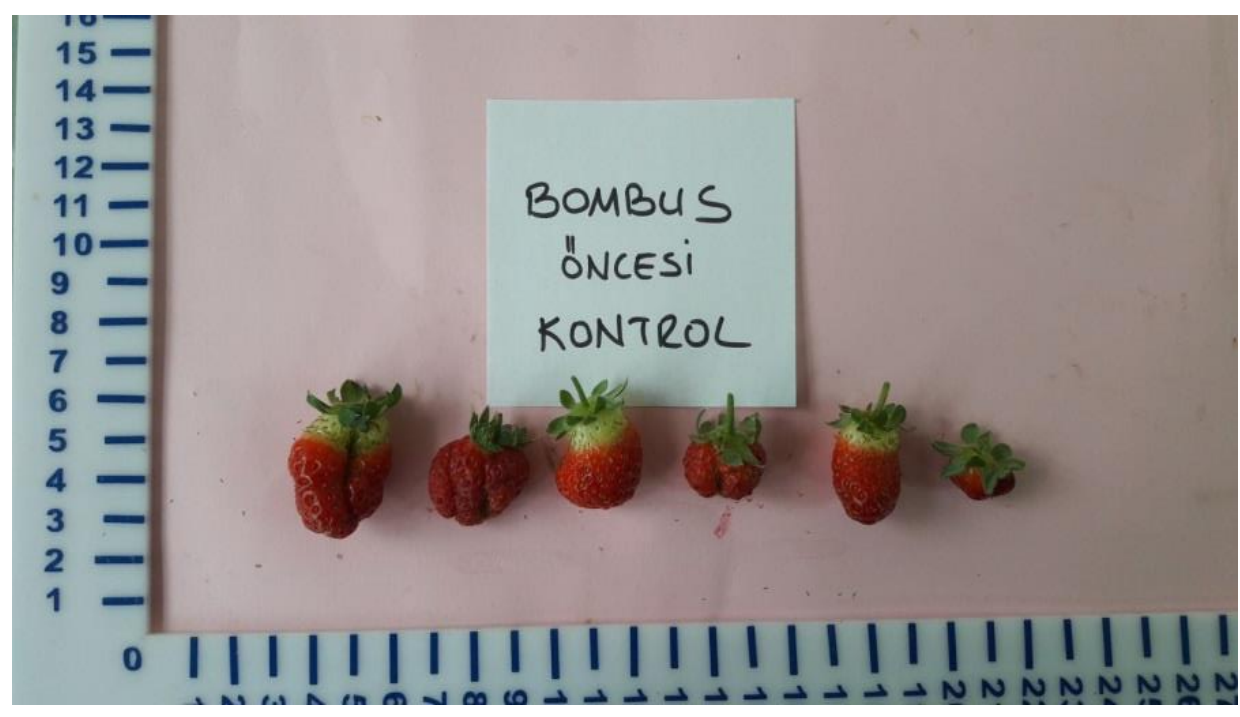

Şekil 3. Bombus arılarından önce kontrol uygulamasına ait meyveler

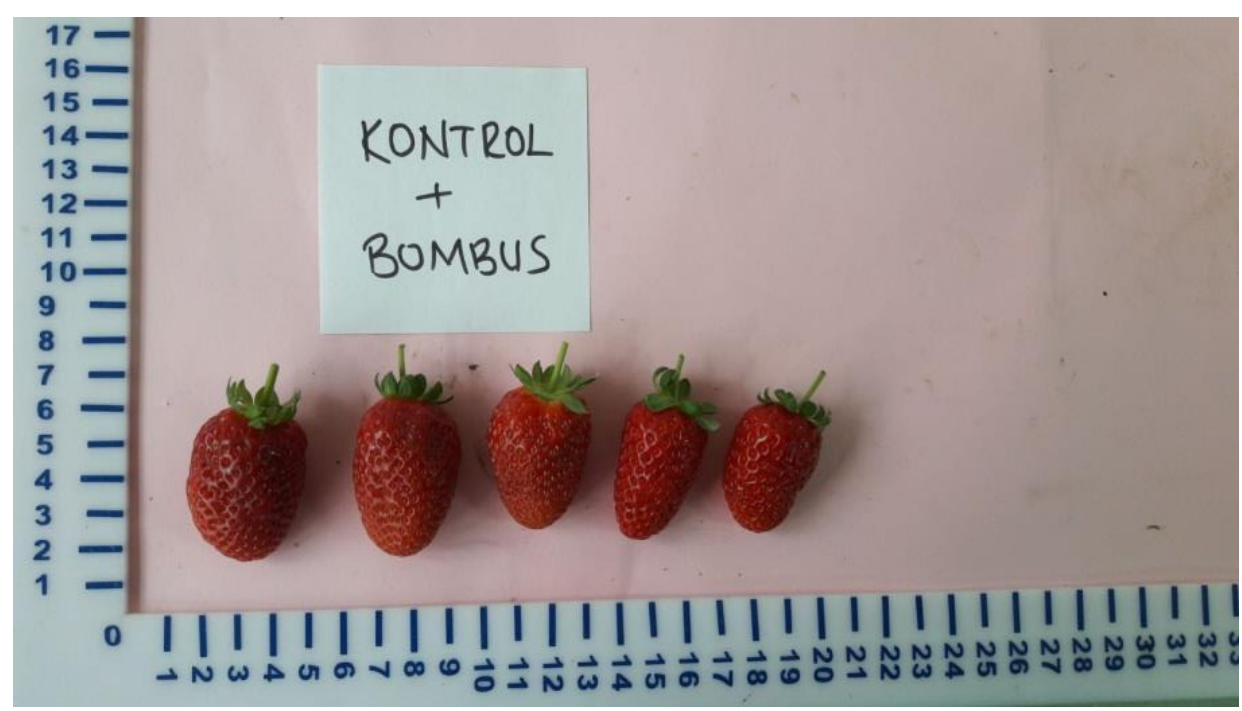

Şekil 4. Bombus arılarından sonra kontrol uygulamasına ait meyveler

Bombus arı faaliyetinin öncesinde ve sonrasında alınan çilek meyvelerinden elde edilen biyokimyasal analiz sonuçlarına ait ortalamalar Tablo 1' de sunulmuştur.

Tablo 1. Albion çeşidine ait çilek meyvelerinin bazı biyokimyasal madde içerikleri

\begin{tabular}{|l|l|l|l|l|}
\hline \multirow{2}{*}{ Parametreler } & \multicolumn{2}{l|}{ Bombus'tan önce } & \multicolumn{2}{l|}{ Bombus'tan sonra } \\
\cline { 2 - 6 } & Kontrol & Organik Gübre & Kontrol & Organik Gübre \\
\hline SÇKM (\%) & $7,26 \pm 0,21$ & $7,21 \pm 0,51$ & $9,90 \pm 0,45$ & $8,96 \pm 0,83$ \\
\hline $\mathrm{pH}$ & $2,17 \pm 0,05$ & $2,17 \pm 0,05$ & $2,20 \pm 0,01$ & $2,20 \pm 0,01$ \\
\hline $\begin{array}{l}\text { Titre edilebilir asitlik (\%) } \\
\text { (sitrik asit cinsinden) }\end{array}$ & $0,45 \pm 0,05$ & $0,38 \pm 0,05$ & $0,30 \pm 0,03$ & $0,28 \pm 0,03$ \\
\hline Malik asit (\%) & $0,10 \pm 0,77$ & $0,11 \pm 0,32$ & $0,11 \pm 0,30$ & $0,12 \pm 0,10$ \\
\hline C vitamini (mg/100ml) & $36,83 \pm 6,13$ & $29,52 \pm 0,30$ & $37,50 \pm 3,27$ & $35,38 \pm 3,40$ \\
\hline $\begin{array}{l}\text { Toplam şeker } \\
\text { (glikoz+fruktoz)(\%) }\end{array}$ & $1,70 \pm 0,16$ & $1,44 \pm 0,10$ & & \\
\hline
\end{tabular}




\subsection{SÇKM (Suda çözünebilir kuru madde miktarı)}

Analiz sonuçlarına göre SÇKM miktarları bakımından hem organic gübre uygulamasında hem de kontrol grubunda Bombus arılarının faaliyeti sonrasında artış belirlenmiştir. Kontrol uygulamasinda Bombustan önce \%7,26 olan SÇKM değeri Bombustan sonra \%9,90'a; Organik gübre uygulamasında $\% 7,21$ olan SÇKM değeri ise Bombustan sonra \%8,96' ya yükselmiştir. Çilek meyvelerinde suda çözünür kuru madde içeriğinin organik yetiştiricilikte daha yüksek olduğu bilinmektedir (Balc1, 2005). Buna ilaveten bombus arılarının tozlaşmaya etkisi ve iyi bir döllenmenin meydana gelişinin sonucu olarakta SÇKM miktarının arttığı düşünülebilir.

\section{2. $\mathrm{pH}$}

Her iki uygulama grubunda da Bombus'tan önce 2,17 olan $\mathrm{pH}$ değeri Bombustan sonra 2,20 olarak belirlenmiştir. Bombus arı faaliyetinin çilek meyvelerindeki $\mathrm{pH}$ içeriği üzerine ciddi bir farklılığa neden olmadığı söylenebilir.

\subsection{Titre edilebilir asitlik}

Bombus faaliyetinden önce Kontrol grubu meyvelerinde $\% 0,45$ olan değer bombus faaliyetinden sonra \%0,30'a düşerken; organik gübre uygulamasinda Bombustan önce $\% 0,38$ olan bu değer arı faaliyeti sonrasında \% 0,28'e düşmüştür. Nitekim Ürdün'de sera şartlarında Honor çilek çeşidi ile yapılan çalışmada titre edilebilir asit miktarının geleneksel olarak yetiştirilen meyvelerde organik şartlarda yetiştirilenlere göre daha yüksek olduğu bildirilmiştir (Abu-Zahra vd., 2006). Aynı sonuç Brezilya'da Sweet Charlie çeşidinde yapılan bir çalışmada da elde edilmiştir (Camergo vd., 2009).

\subsection{Vitamin C (Askorbik asit)}

Vitamin C içeriği bakımından Bombus öncesinde kontrolde $36,83 \mathrm{mg} / 100 \mathrm{ml}$ olan değer Bombustan sonra $37,50 \mathrm{mg} / 100 \mathrm{ml}$ olarak belirlenmiştir. Organik gübre uygulamasinda bombustan önce $29,52 \mathrm{mg} / 100 \mathrm{ml}$ olan Vitamin $\mathrm{C}$ içeriği ise Bombustan sonra yine artarak 35,38 mg/100ml olarak tespit edilmiştir. Benzer şekilde Balc1 (2005) çilekte yaptığı çalışmada Vitamin C içeriğinin organik yetiştiricilikte klasik yetiştiriciliğe oranla daha yüksek olduğunu belirlemiştir. Akdeniz üniversitesinde yapılan bir çalışmada, örtüaltında topraksız çilek (Fragaria $\times$ ananassa Duch.) yetiştiriciliğinde
Vitamin C değerleri 59,70 ile $61,87 \mathrm{mg} / 100 \mathrm{ml}$ arasinda (Adak ve Pekmezci, 2012), yine Akdeniz Üniversitesi Tohumculuk Araştırma ve Geliştirme Merkezine ait cam serada Camarosa çilek çeşidinde yapılan bir çalışmada 58.67 ile 60.50 $\mathrm{mg} / 100 \mathrm{ml}$ arasinda (Adak, 2010), Ege Üniversitesi, Bergama Meslek Yüksekokulu Seracılık Programına ait PE örtülü serada farklı ortam kültürleri ile yapılan çilek yetiştiriciliğinde 22,34 ile $27,87 \mathrm{mg} / 100 \mathrm{ml}$ arasinda (Eltez ve Tüzel, 2007) tespit edilmiştir. Sera şartlarında yapılan bizim çalışmamızda elde edilen Vitamin C içerikleri mevcut literatür sonuçlarına yakın değerlerde bulunmaktadır.

\subsection{Toplam şeker (glikoz+fruktoz)}

Çilek meyvelerindeki toplam şeker miktarları Bombus sonrasinda hem control grubunda hem de organic gübre uygulamasında önemli derecede artış göstermiştir. Kontrol grubu meyve örneklerinde bombus öncesinde \%1,70 toplam şeker miktarı elde edilirken bu değer bombus sonrasında önemli bir artış ile \%2,75 olarak belirlenmiştir. Yine organik gübre uygulamsında bombustan önce $\% 1,44$ olan toplam şeker içeriği bombustan sonra \%2,45'e ulaşmıştır. Nitekim Wang ve Lin (2002) Honeoye ve Allstar çilek çeşitleriyle yaptıkları kompost çalışmasında kompost kullanımının toplam şeker içeriğini önemli derecede artırdığını belirtmişlerdir.

\section{Sonuç}

Sonuç olarak, sera şartlarında yapılan bu deneme ile hem organik gübrenin etkinliği hem de tozlanmada önemli role sahip olan Bombus arılarının etkinliği karşılaştırılmıştır. Elde edilen bulgular Bombus arılarının faaliyetiyle çilek meyvelerindeki önemli bazı biyokimyasal içeriklerinde artış sağlandığı belirlenmiştir. $\mathrm{Bu}$ sonuçlar mevcut literatürlerle uyum içerisinde olmuştur. Bombus arılarının tozlanma da kullanımı ile bitkisel üretimde meyve iriliği ve kalitenin ve buna bağlı olarakta verim artışının yanısıra meyvelerin biyokimyasal içeriklerinin iyileştirilmesininde mümkün olacağı kanısına varılmıştır.

\section{Kaynaklar}

Abu-Zahra, T., R., Al-Ismail, K., Shatat, F., 2006. Effect of Organic and Conventional Systems on Fruit Quality of Strawberry (Fragaria x ananassa duch) Grown under plastic house conditions in the Jordan Valley. Acta Horticulturae, 741, 159171. 
Adak, N., 2010. Camarosa Çilek Çeşidinde Değişik EC Düzeylerinin Verim ve Kalite Üzerine Etkileri, Batı Akdeniz Tarımsal Araştırma Enstitüsü Derim Dergisi, 27(2):22-33.

Adak, N., Pekmezci, M., 2012. "Topraksız Çilek Yetiştiriciliğinde Fide Tipi ve Yetiştirme Ortamının Meyve Kalitesi Üzerine Etkileri". Ege Üniversitesi Ziraat Fakültesi Dergisi 49 / 2 :135-142.

Ağaoğlu, Y.S., 1986. Üzümsü Meyveler. Ankara Üniversitesi, Ziraat Fak.,Yayınları: 984. Ders Kitabı: 290., Ankara, 377 s.

Aybak, H.Ç., 2005. Çilek Yetiştiriciliği, Hasad Yayıncılık, İstanbul.

Balc1, G., 2005. Klasik ve Organik Çilek Yetiştiriciliğinin Verim, Kalite ve Karlılık Yönünden Karşılaştırılması Üzerine Bir Araştırma. Yüksek Lisans Tezi, Ondokuz Mayıs Üniversitesi Fen Bilimleri Enstitüsü, Samsun.

Camargo, LKP., Resende J.T.V., Galvao, A.G., Baier, J.E., Faria, M.V., Camargo C.K., 2009. Chemical Characterization of Strawberry Fruits in the Organic and Conventional Croping Systems in Pots, Semina- Ciencias Agrarias Volume:30 Supplement:1, s:993-998.

Dimou, M., Taraza, S., Thrasyvoulou, A., Vasilakakis, M., 2008. Effect of bumble bee pollination on greenhouse strawberry production. Journal of Apicultural Research. Volume 47: (2), p: 99101.

Eltez, R.Z., Tüzel, Y., 2007. "Merdiven Tipi Sistemde Farklı Topraksız Tarım Tekniklerinin Sera Çilek Yetiştiriciliğinde Verim ve Kaliteye Etkileri". Ege Üniversitesi Ziraat Fakültesi Dergisi 44 / 1: $15-27$.

Fliszkiewicz, F., Giejdasz, G., Wilkaniec, Z., 2011. The importance of male red mason bee (Osmia rufa L.) and male bufftailed bumblebee (Bombus terrestris L.) pollination in blackcurrant (Ribes nigrum L.). The Journal of Horticultural Science and Biotechnology, 86:5, 457-460,

DOI: $10.1080 / 14620316.2011 .11512788$

Gajc-Wolska, J., Kowalczyk, K., Mikas, J., Drajski, R., 2011. Efficiency of Cucumber (Cucumis sativus L.) Pollination by Bumblebees (Bombus terrestris). Acta Sci. Pol., Hortorum Cultus 10(1) 2011, p: 159-169.

Mommaerts, V., Put, K., Smagghea, G., 2011. Bombus terrestris as pollinator-and-vector to suppress Botrytis cinerea in greenhouse strawberry. Pest Manag Sci 2011; 67, p:1069-1075.

Özkan, G., 2012. Erzurum (Merkez) Koşullarında Organik Çilek Yetiştiriciliği İmkanları Üzerinde Bir Araştırma. Doktora Tezi, Atatürk Üniversitesi Ziraat Fakültesi Fen Bilimleri Enstitüsü, Erzurum, 116s.

Paydas, S., Eti, S., Kaftanoglu, O., Yasa, E., Derin, K., 1998. Effects of Pollination of Strawberries Grown in Plastic Greenhouses by Honeybees and Bumblebees on The Yield and Quality of The Fruits.

DOI: 10.17660/ActaHortic.1998.513.53

Rolda'n Serrano, A., Guerra Sanz, J.M., 2006. Quality fruit improvement in sweet pepper culture by bumblebee pollination. Scientia Horticulturae (110) 160-166.

Wang, S. Y., Lin, S. S., 2002. Composts as soil supplement enhanced plant growth and fruit quality of strawberry. Journal of Plant Nutrition 25(10): p.2243-2259.

Zisovich, A. H., Goldway, M., Schneider, D., Steinberg, S., Stern, E., Stern, R. A., 2012. Adding bumblebees (Bombus terrestris L., Hymenoptera: Apidae) to pear orchards increases seed number per fruit, fruit set, fruit size and yield, The Journal of Horticultural Science and Biotechnology, 87:4, 353-359, DOI: $10.1080 / 14620316.2012 .11512876$ 